\title{
Vanadium (V) reduction reaction on modified glassy carbon electrodes - role of oxygen functionalities and microstructure
}

\author{
Susan M. Taylor ${ }^{\text {a }}$, Alexandra Pătru ${ }^{\text {a, }}$, Daniel Streich ${ }^{\text {a }}$, Mario El Kazzi ${ }^{\text {a }}$, Emiliana Fabbri a \\ Thomas J. Schmidt ${ }^{\text {a,b }}$ \\ ${ }^{\text {a} E l e c t r o c h e m i s t r y ~ L a b o r a t o r y, ~ P a u l ~ S c h e r r e r ~ I n s t i t u t, ~} 5232$ Villigen PSI, Switzerland \\ baboratory of Physical Chemistry, ETH Zürich, 8093 Zürich, Switzerland
}

\begin{abstract}
This paper provides valuable insights into the kinetics of the vanadium (V) reduction reaction occurring at a glassy carbon (GC) model electrode surface treated by different oxidative and mechanical methods. Oxidative treatments were applied by thermal, acid and electrochemical means. Mechanical polishing on an abrasive sandpaper surface was used to prepare a rough GC electrode, this surface was also further electrochemically oxidised. The resulting surfaces were studied by x-ray photoelectron spectroscopy (XPS), Raman spectroscopy, cyclic voltammetry (CV) and electrochemical impedance spectroscopy (EIS). Activity is defined in terms of peak potential separation $\left(\Delta \mathrm{E}_{\mathrm{p}}\right)$ and this descriptor was verified by EIS. No correlation between activity and oxygen to carbon ratio $(\mathrm{O} / \mathrm{C})$ or any specific oxygen functional group was found in this study. Raman spectroscopy revealed significant structural changes for GC electrodes treated by electrochemical oxidation and abrasive polishing. A correlation between structural disorder in GC and improvements in activity was observed. However, a limit of structural disorder exists, beyond which no substantial improvements in activity can be achieved.
\end{abstract}

${ }^{*}$ Corresponding author: Tel +41563102318. Email: alexandra.patru@psi.ch (Alexandra Pătru) 


\section{Introduction}

Redox flow battery (RFB) technologies have risen to prominence as a potential energy storage device for excess energy from renewable sources [1]. The all-vanadium system is one of the most well-researched technologies in the field. There are numerous full-size systems in operation around the world and research efforts into this technology are on the rise with several niche applications emerging [2-4]. Research is focused primarily on reducing overall material and component costs and improving system performance [5]. The design and optimisation of the carbon electrode materials has gained significant attention in this field over the past few years. Researchers have focused on improving electron transfer kinetics of the respective redox reactions by modifying the carbon electrode surface properties [6-9]. Improvements in electrode activity have been attributed to the presence of surface oxygen functional groups thought to serve as active sites, facilitating the electron transfer step. However, more recent studies have refuted the role of oxygen functionalities as electro-active sites. These studies suggest that there may be other factors affecting activity including surface wettability, carbon microstructure, roughness and surface area effects [10-13]. Correlations between carbon structure and $\mathrm{sp}^{2}$ carbon content have been related to improvements in activity [11]. It has been shown by several authors that edge-sites are more active than basal sites for both $\mathrm{V}(\mathrm{II})$ oxidation and $\mathrm{V}(\mathrm{V})$ reduction $[10,14$, 15]. These studies on different carbon surfaces have indicated that the kinetics of the vanadium redox reactions depend strongly on the type of carbon used and on the preparation of the electrode surface itself $[13,16]$. While oxygen functionalities could play a role in improving wetting properties of the electrode surface, their role as electroactive sites remains unclear. The vast array of literature detailing kinetic studies on different carbon materials employing differing experimental conditions makes it difficult to compare and draw concrete conclusions on this topic. It is critical to gain a better understanding of the reaction kinetics of both the redox reactions involved in the system if the system is to be fully optimised.

It is the purpose of this study to systematically investigate the role of oxygen functional groups and carbon microstructure, on the activity for the $\mathrm{V}(\mathrm{V})$ reduction reaction. A model glassy carbon electrode surface was used in this study. The effects of oxygen functionalisation by three well-known oxygen treatment methods, on the activity of $\mathrm{V}(\mathrm{V})$ reduction was investigated. Mechanical polishing on an abrasive surface was used to prepare a rough GC electrode, this 
surface was also further electrochemically oxidised. Electrode activity was determined by cyclic voltammetry in terms of potential peak separation $\left(\Delta \mathrm{E}_{\mathrm{p}}\right)$. EIS measurements were performed to validate the $\Delta \mathrm{E}_{\mathrm{p}}$ activity descriptor. Surface oxygen to carbon ratios $(\mathrm{O} / \mathrm{C})$ were determined by XPS and structural changes were probed by Raman spectroscopy. Correlations between activity, oxygen to carbon ratio $(\mathrm{O} / \mathrm{C})$ and carbon microstructure of the different $\mathrm{GC}$ surfaces in this study are discussed.

\section{Experimental}

\subsection{Electrolyte preparation}

The $\mathrm{V}(\mathrm{V})$ electrolyte was prepared by dissolving $1 \mathrm{M} \mathrm{VOSO}_{4} \cdot \mathrm{nH}_{2} \mathrm{O}$ (Alfa Aesar $99.9 \%$, where $\mathrm{n}=3$ determined by thermogravimetric analysis) in $2 \mathrm{M} \mathrm{H}_{2} \mathrm{SO}_{4}$ (Sigma Aldrich 99.999\%). A commercial redox flow cell system $\left(\right.$ Scribner $^{\circledR}$ ) with a cell active area of $25 \mathrm{~cm}^{2}$, carbon paper electrodes (Sigracet ${ }^{\circledR}$ GDL 39AA, Ion Power inc.) and a Nafion ${ }^{\circledR} 117$ membrane was used to charge the $1 \mathrm{M} \mathrm{VOSO} 4 \cdot \mathrm{nH}_{2} \mathrm{O}$ solution to $\mathrm{V}$ (II) (negative electrode) and $\mathrm{V}(\mathrm{V}$ ) (positive electrode). The solutions were considered to be fully charged when the current density reached a value of $2 \mathrm{~mA} / \mathrm{cm}^{2}$. The concentration of the $\mathrm{V}(\mathrm{V})$ solution was determined by UV-visible spectroscopy (Metrohm ${ }^{\circledR} \mathrm{UV}$-visible spectrometer) to be $0.9 \mathrm{M}$.

\subsection{Electrode materials and treatment methods}

Glassy carbon (GC) disk electrodes were purchased from Hochtemperaturwerkstoffe $\mathrm{GmbH}$ (Sigradur ${ }^{\circledR}$, pyrolysed at $1000^{\circ} \mathrm{C}, 5 \mathrm{~mm}$ OD x $4 \mathrm{~mm}$ thickness, mirror polished). All disk inserts were compatible with the standard E4 series RDE tips from Pine Instruments Co. The GC electrodes were treated by different oxidative and mechanical methods to produce six GC electrode samples including the pristine GC sample. Oxidative treatments were carried out following three standard oxidative treatment methods: (i) electrochemical oxidation in $2 \mathrm{M}$ $\mathrm{H}_{2} \mathrm{SO}_{4}$ solution, by potential holding at $2.2 \mathrm{~V} / \mathrm{RHE}$ for 5 minutes followed by another potential holding at $0.1 \mathrm{~V} / \mathrm{RHE}$ for 30 seconds, while rotating at $1000 \mathrm{rpm}$ [17] (ii) heat treatment at $400^{\circ} \mathrm{C}$ in a tube furnace under $\mathrm{O}_{2}$ atmosphere for 1 hour [12] $\left(\mathrm{O}_{2}\right.$ flow rate $30 \mathrm{~mL} / \mathrm{min}$ ), (iii) acid treatment in a 3:1 concentrated $\mathrm{H}_{2} \mathrm{SO}_{4} / \mathrm{HNO}_{3}$ (Sigma Aldrich 99.999\%) solution at $60^{\circ} \mathrm{C}$ for 30 minutes [18]. Mechanical surface modification was carried out by manual polishing on an abrasive sandpaper surface ( $3 \mathrm{M}^{\mathrm{TM}}$ sandpaper, Grit size-600) to produce a rough GC surface. A 
second rough GC electrode was prepared and further electrochemically oxidised following the same method described previously. Two electrode samples were prepared by each treatment method, one electrode sample was characterised electrochemically and the other electrode sample was characterised by x-ray photoelectron spectroscopy (XPS) and Raman spectroscopy without seeing any $\mathrm{V}(\mathrm{V})$ electrolyte. The nomenclature used throughout the text for the differently treated GC electrodes is summarised in table 1.

Table 1 - Electrode sample names and corresponding nomenclature.

\begin{tabular}{l|l}
\hline Electrode & Acronym \\
\hline Pristine glassy carbon & GC-P \\
Heat treated glassy carbon & GC-H \\
Acid treated glassy carbon & GC-A \\
Electrochemically oxidised glassy carbon & GC-EC \\
Rough glassy carbon & GC-R \\
Rough glassy carbon followed by electrochemical oxidation (mixed treatment) & GC-R+EC \\
\hline
\end{tabular}

\subsection{Physical Characterisation}

\subsubsection{X-ray photoelectron spectroscopy (XPS)}

The surface oxygen to carbon ratio $(\mathrm{O} / \mathrm{C})$ and the type of oxygen functional groups were investigated by XPS. The measurements were performed using a VG ESCALAB 220iXL spectrometer (Thermo Fischer Scientific) equipped with an Al-Ka monochromatic source (spot size: $500 \mu \mathrm{m}$; power: $150 \mathrm{~W}$ ) and a magnetic lens system. The base pressure of the system was typically $1 \times 10^{-9}$ mbar and the electron emission angle was $90^{\circ}$. A Shirley type background subtraction was applied and all curves were fitted according to a Gaussian-Lorentzian function. Survey spectra were initially recorded at low resolution, and subsequently high resolution spectra of the $\mathrm{C} 1 \mathrm{~s}$ and $\mathrm{O} 1 \mathrm{~s}$ peaks were collected to determine the surface oxygen to carbon ratio $(\mathrm{O} / \mathrm{C}$ ratio) for all electrode samples. Deconvolution of the $\mathrm{C} 1 \mathrm{~s}$ core level spectra was carried out fitting the following peaks: $284.1 \mathrm{eV}, 284.9 \mathrm{eV}, 285.96 \mathrm{eV}, 288.2 \mathrm{eV}, 290.4 \mathrm{eV}$ and $291.61 \mathrm{eV}$ which arise from $\mathrm{C}-\mathrm{C}, \mathrm{C}-\mathrm{H}, \mathrm{C}-\mathrm{OR}$ (including $\mathrm{C}-\mathrm{OH}$ and $\mathrm{O}-\mathrm{C}-\mathrm{O}$ ), $\mathrm{C}=\mathrm{O}, \mathrm{COOH}$ and shakeup 
satellite contributions respectively $[19,20]$ (see Fig. S1 for curve fitting, Section 1.1 supplementary information).

\subsubsection{Raman Spectroscopy}

A Raman microscope (Labram HR800 Horiba-Jobin Yvon, Japan) with a He-Ne laser $(632.8 \mathrm{~nm})$ and a 50x objective (ULWDMS Plan 50, NA $=0.55$, Olympus, Japan) was used to investigate the near-to-surface region of the GC electrodes in this study. The measurements were performed with a grating of 600 line/mm and a laser power of $20 \mathrm{~mW}$. First order Raman spectra were recorded in the range 1000 to $2000 \mathrm{~cm}^{-1}$.

\subsection{Electrochemical characterisation}

All experiments were carried out in a standard three-electrode setup using a platinum-mesh counter electrode and an $\mathrm{Hg} / \mathrm{Hg}_{2} \mathrm{SO}_{4}$ reference electrode (Gamry instruments Inc.) at room temperature. The cyclic voltammograms (CVs) as well as electrochemical impedance spectroscopy (EIS) were recorded using a Biologic SP-300 potentiostat. Before each experiment, the electrolyte was de-aerated by bubbling with argon for 20 minutes. The argon atmosphere was maintained in the electrochemical cell during measurements. CVs of all electrodes were measured firstly in $2 \mathrm{M} \mathrm{H}_{2} \mathrm{SO}_{4}$ at $50 \mathrm{mV} / \mathrm{s}$ between 0.05 and $1.0 \mathrm{~V} / \mathrm{RHE}$ at a scan rate of 50 $\mathrm{mV} / \mathrm{s}$ (see Fig. S2 in supplementary information). CVs were then recorded in $0.9 \mathrm{M} \mathrm{V(V)/2} \mathrm{M}$ $\mathrm{H}_{2} \mathrm{SO}_{4}$ electrolyte solution, scanning from $1.7 \mathrm{~V} / \mathrm{RHE}$ to $0.5 \mathrm{~V} / \mathrm{RHE}$ at $50 \mathrm{mV} / \mathrm{s}$ recording the third scan. A fresh $\mathrm{V}(\mathrm{V})$ solution was used before each $\mathrm{CV}$ measurement. All CVs were corrected for ohmic resistance, with a typical résistance of $3 \mathrm{ohms}$ being measured for all CVs measured in vanadium (V) solution. All CV data is reported against the reversible hydrogen electrode scale (RHE). Impedance spectra were recorded with a voltage amplitude of $10 \mathrm{mV}$ in the frequency range of $1 \mathrm{MHz}-50 \mathrm{mHz}$ in potentiostatic mode at $\sim 10 \mathrm{mV}$ overpotential for the $\mathrm{V}(\mathrm{V})$ reduction reaction. The experimental data were fitted to the equivalent electrical circuit by a randomize-simplex procedure using $\mathrm{Z}$ Fit EC Lab ${ }^{\circledR}$ software. 


\section{Results and Discussion}

\subsection{Surface and structural characterisation}

\subsubsection{XPS analysis}

The results from the XPS analysis are summarised in Fig. 1 showing the surface oxygen to carbon ratio of all the GC electrode samples (Fig. 1a) and the contribution of each oxygen species to the total oxygen content (Fig. 1b.)
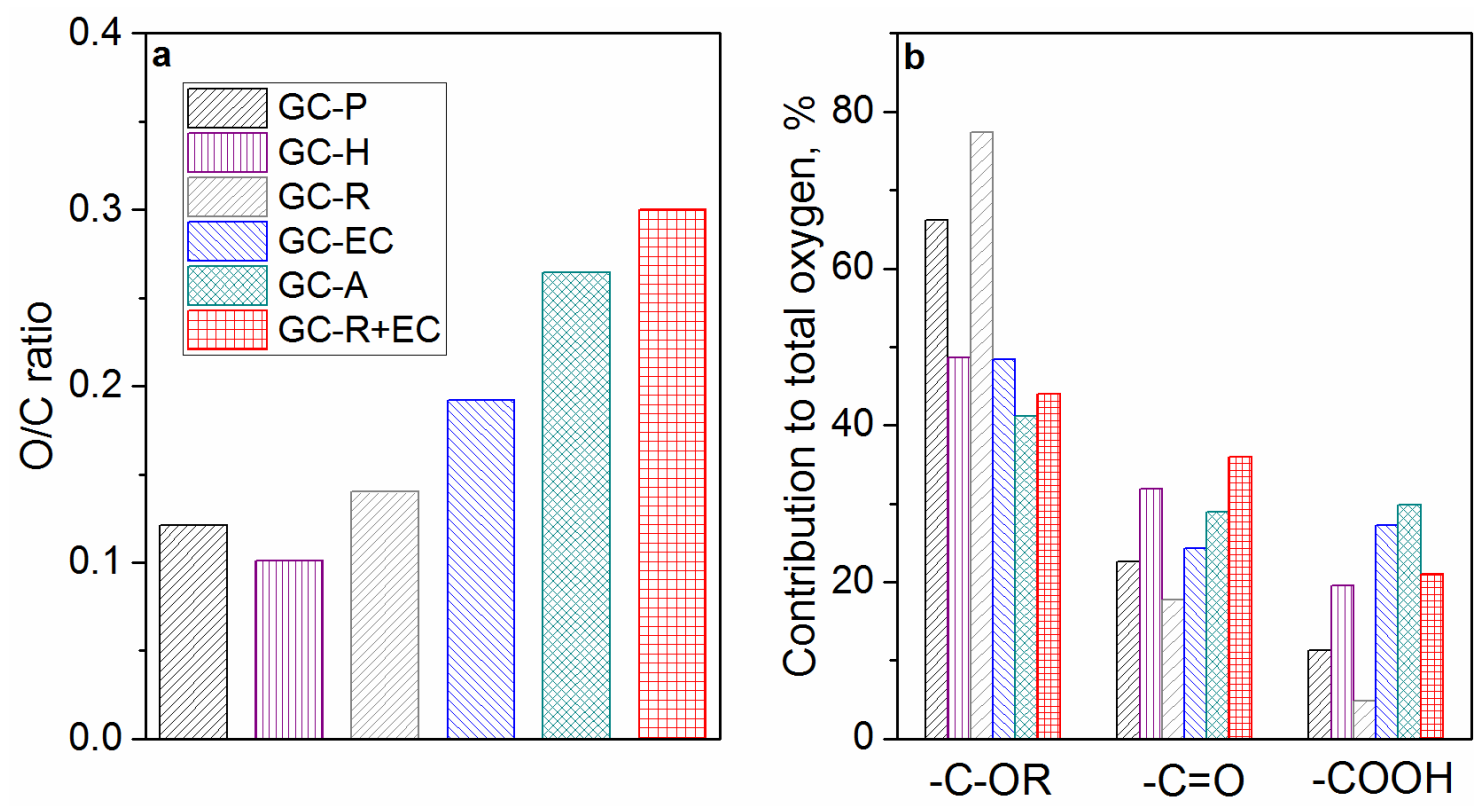

Fig. 1 - (a) Surface oxygen to carbon ratios (O/C) and (b) \% contribution of each surface oxygen group to the total surface oxygen for pristine glassy carbon (GC-P), heat treated glassy carbon (GC-H), rough glassy carbon (GC-R), electrochemically oxidised glassy carbon (GC-EC), acid treated glassy carbon (GC-A) and rough glassy carbon followed by electrochemical oxidation (mixed treatment) $(\mathrm{GC}-\mathrm{R}+\mathrm{EC})$.

No oxygen was introduced onto the surface of the heat treated GC electrode $(\mathrm{GC}-\mathrm{H})$ which showed a similar O/C ratio to the GC-P. A small amount of oxygen was introduced onto the GC-R after mechanical polishing. The surface $\mathrm{O} / \mathrm{C}$ ratio increased the most for the GC-A, GCEC and GC-R+EC electrodes after treatment, with the mixed treatment (GC-R+EC) showing the highest $\mathrm{O} / \mathrm{C}$ ratio out of all the GC samples. Fig. $1 \mathrm{~b}$ shows that the relative amounts of carbonyl $(\mathrm{C}=\mathrm{O})$ and carboxyl $(\mathrm{COOH})$ groups increased in all samples after treatment except for the GC- 
$\mathrm{R}$. The effect of surface oxygen groups on electrochemical activity for $\mathrm{V}(\mathrm{V})$ reduction will be discussed in the following sections.

\subsubsection{Raman spectroscopy}

Glassy carbon is a partially graphitised form of carbon suggested to have a turbostratic structure (i.e. layers of graphite-type microcrystallite regions connected by disordered regions) [21]. There are two main signals of interest in the first order Raman spectra of the carbon materials investigated here, namely the D-band and G-band. The D-band occurs at around $1360 \mathrm{~cm}^{-1}$ and is associated with the defect concentration or "disorder" in the carbon material. The G-band occurring at $\sim 1580-1600 \mathrm{~cm}^{-1}$ relates to graphitic or "ordered" domains in the carbon structure $[21,22]$. In general, the $\mathrm{I}_{\mathrm{D}} / \mathrm{I}_{\mathrm{G}}$ intensity ratio is used as a descriptor to assess the degree of amorphisation or graphitisation of a carbon material [23]. In the case of transitions from nanocrystalline graphite towards amorphous carbons, a decrease in $\mathrm{I}_{\mathrm{D}} / \mathrm{I}_{\mathrm{G}}$ intensity ratio has been observed previously $[22,24]$. For amorphous carbons, D-band broadening is correlated with disorder in the carbon structure and is related to different distributions of clusters with different ring orders other than six $[21,25,26]$. Raman spectroscopy was used to probe any changes in the near surface microstructure of GC after the different treatment methods. Distinct G- and D-band peaks can be identified in the first order Raman spectra of all the GC electrodes shown in Fig. 2. The D-band shows a higher peak intensity compared to the G-band in all samples $\left(I_{D} / I_{G}>1\right)$, this observation is in line with several literature studies on glassy carbon $[20,27,28]$. All $\mathrm{I}_{\mathrm{D}} / \mathrm{I}_{\mathrm{G}}$ intensity ratios (in terms of peak intensities) are summarised in Table 2 together with the corresponding FWHM $\left(\mathrm{cm}^{-1}\right)$ as an indicator for peak width. 

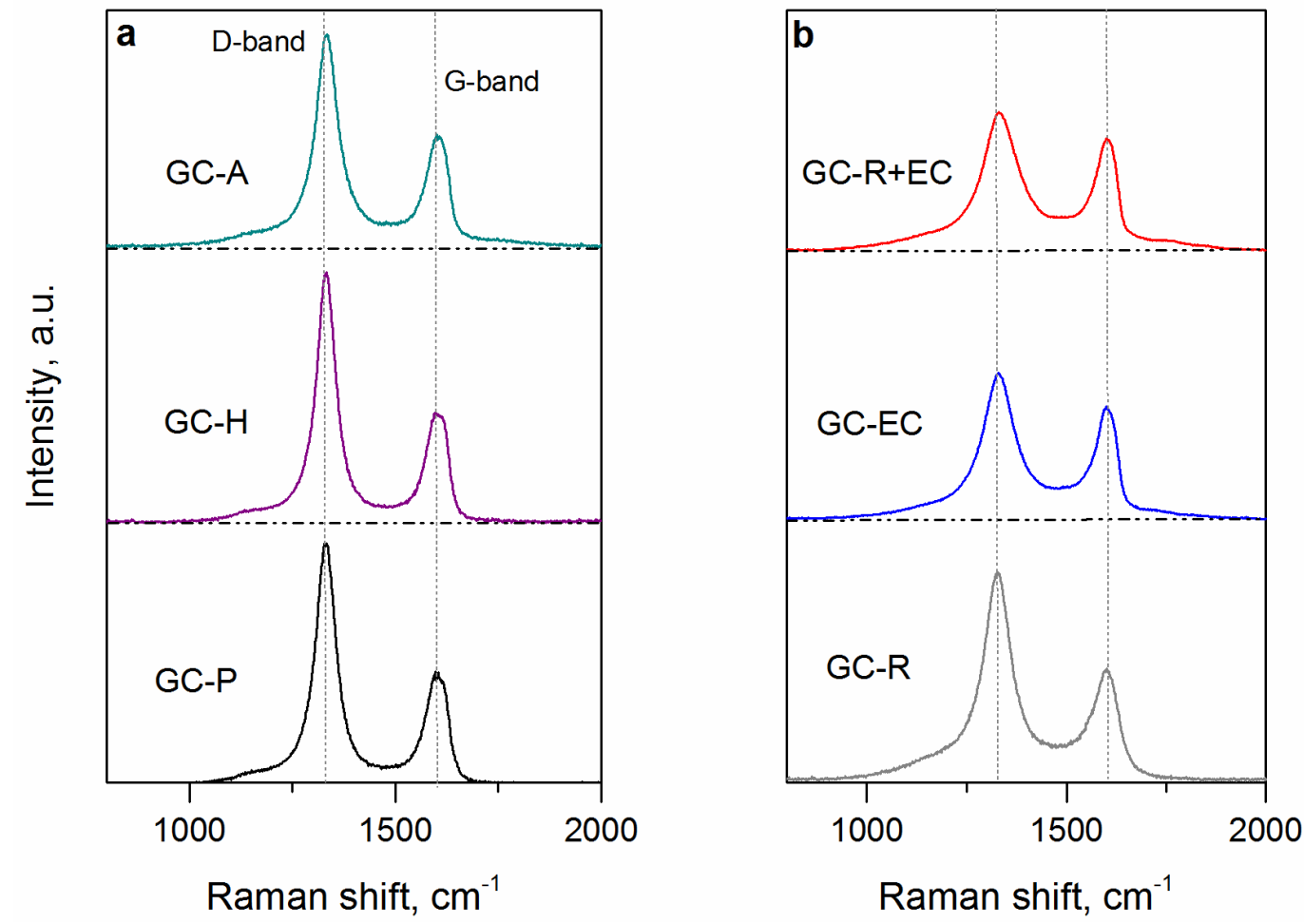

Fig. 2 - Raman spectra of (a) GC-P, GC-H and GC-A (b) GC-R, GC-EC and GC-R+EC normalised to the G-band intensity maxima.

Table 2 - ID/Ig peak intensity ratios and peak widths (full width at half maximum, FWHM $\mathrm{cm}^{-1}$ ) from the Raman spectra of all GC sample electrodes.

\begin{tabular}{|c|c|c|c|}
\hline Electrode & $\mathbf{I}_{\mathbf{D}} / \mathbf{I}_{\mathbf{G}}$ & FWHM D-band $\left(\mathrm{cm}^{-1}\right)$ & FWHM G-band $\left(\mathrm{cm}^{-1}\right)$ \\
\hline GC-P & 2.21 & 60.3 & 67.2 \\
\hline GC-H & 2.23 & 57.2 & 66.3 \\
\hline GC-A & 1.96 & 66.1 & 67.5 \\
\hline GC-R & 1.87 & 85.4 & 85.2 \\
\hline GC-EC & 1.32 & 101 & 71.0 \\
\hline GC-R+EC & 1.24 & 114 & 75.0 \\
\hline
\end{tabular}

In the case of both the GC-A and GC-H no significant changes in the Raman spectra were observed in Fig. 2a relative to GC-P, only a slight decrease in the $\mathrm{I}_{\mathrm{D}} / \mathrm{I}_{\mathrm{G}}$ ratio for the GC-A was seen. This suggests that both the acid and heat treatment methods were not aggressive enough to induce any significant structural changes observable by Raman spectroscopy. However, the 
Raman spectra of the GC-R, GC-EC and GC-R+EC samples in Fig. 2b, show significant changes after treatment. The most noticeable changes in the Raman spectra of the three samples is the peak broadening and the consequent decrease in the $I_{D} / I_{G}$ intensity ratio (Table 2 ). In this case, the decrease in $\mathrm{I}_{\mathrm{D}} / \mathrm{I}_{\mathrm{G}}$ ratio corresponds to an increase in amorphisation and disorder in the GC surface. The peak broadening of the D-band further confirms the defect introduction for these three samples [22]. The D- and G-bands also begin to overlap and the region around $1500 \mathrm{~cm}^{-1}$ begins to increase in intensity as the two bands merge. Sadezky and co-workers have previously assigned signals in this region to the amorphous part of the carbon structure [29]. Thus, the changes observed for these three surfaces result from an increase in the amorphous part of the carbon structure and an increase in structural disorder.

\subsection{Electrochemical characterisation}

\subsubsection{Voltammetric behaviour of modified GC surfaces in $V(V)$ solution}

The $\mathrm{V}(\mathrm{V})$ reduction reaction:

$\mathrm{VO}_{2}^{+}+2 \mathrm{H}^{+}+e^{-} \rightleftharpoons \mathrm{VO}^{2+}+\mathrm{H}_{2} \mathrm{O}$

was investigated at the modified GC electrode surfaces in this study. Peak separation $\left(\Delta \mathrm{E}_{\mathrm{p}}, \mathrm{mV}\right)$ between anodic and cathodic peak potentials was used as the activity descriptor in this study. The reversibility limits proposed by Nicholson were used as a guideline for assessing activity [30]. All GC electrodes showed peak separation values greater than the theoretical value of $59 / \mathrm{n} \mathrm{mV}$, which indicates non-Nernstian behaviour [31] (see Table 3). Fig. 3a shows the CVs obtained on the oxygen treated GC electrodes and Fig. 3b shows the CVs obtained for the GC-R and GC-R+EC surfaces. 

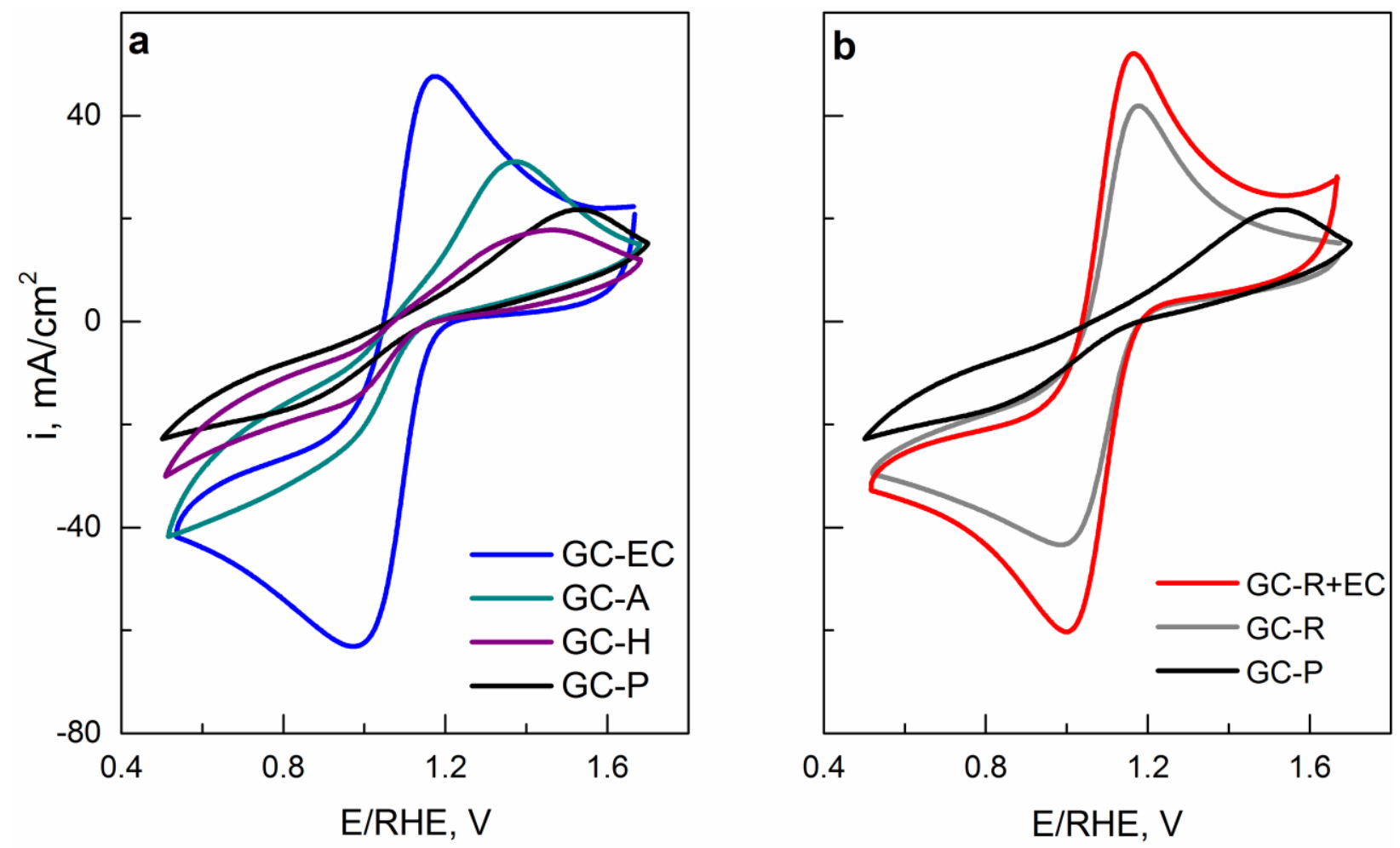

Fig. 3 - Cyclic voltammograms measured at $50 \mathrm{mV} / \mathrm{s}$ in $0.9 \mathrm{M} \mathrm{V}(\mathrm{V}) / 2 \mathrm{M} \mathrm{H} \mathrm{H}_{2} \mathrm{SO}_{4}$ for GC electrodes subject to (a) oxidative treatments and (b) mechanical and mixed treatments.

Table 3 - Activity $\left(\Delta \mathbf{E}_{\mathrm{p}}, \mathrm{mV}\right)$ measured at $50 \mathrm{mV} / \mathrm{s}$.

\begin{tabular}{c|c}
\hline Electrode & Activity $\left(\Delta \mathbf{E}_{\mathbf{p}}, \mathbf{m V}\right)$ \\
\hline GC-R+EC & 165 \\
GC-R & 184 \\
GC-EC & 186 \\
GC-A & 501 \\
GC-H & 700 \\
GC-P & 710 \\
\hline
\end{tabular}

The GC-P, GC-H and GC-A show peak separations $\Delta \mathrm{E}_{\mathrm{p}}>210 \mathrm{mV}$ and fall into the irreversible region, showing poor activity towards $\mathrm{V}(\mathrm{V})$ reduction. The GC-EC, GC-R and GC-R+EC electrodes showed the greatest improvements in activity after treatment $\left(\Delta \mathrm{E}_{\mathrm{p}}<210 \mathrm{mV}\right)$ falling 
into the 'quasi-reversible' region. These three electrodes will be considered for further discussion.

\subsection{Surface area effect on activity $\left(\Delta E_{p}\right)$}

It should be clarified at this point that the peak separation descriptor $\left(\Delta \mathrm{E}_{\mathrm{p}}\right)$ used here, is a purely kinetic parameter related only to the intrinsic catalytic properties of the electrode surface under investigation. Increases in the geometric surface area of a given electrode with a given intrinsic activity, will only contribute to an increase in the peak current intensity measured in a CV. The peak separation itself will remain unchanged. This concept is confirmed in Fig. 4 which shows the peak current and peak separation values $\left(\Delta \mathrm{E}_{\mathrm{p}}\right)$ for an electrode (GC-EC) which has its full geometric area exposed to the electrolyte and a second CV where only half the geometric area is exposed to electrolyte during the CV measurement (See supplementary information section 1.2 for detailed discussion).

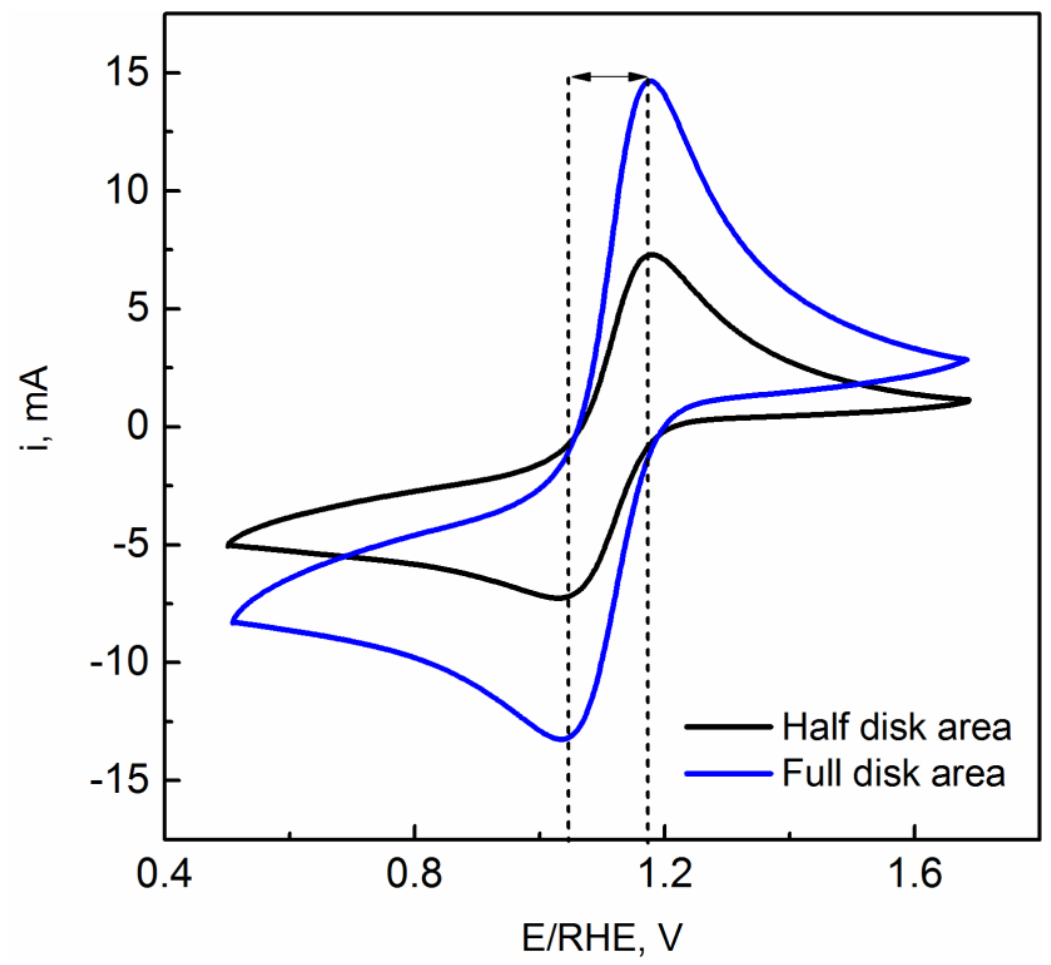

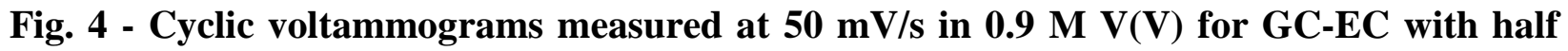
$\left(0.098 \mathrm{~cm}^{2}\right)$ and the full $\left(0.196 \mathrm{~cm}^{2}\right)$ geometric electrode surface area exposed to the electrolyte. 


\subsection{Electrochemical impedance spectroscopy (EIS)}

EIS was used to further investigate and validate the kinetic processes occurring at the electrode/electrolyte interface for the three GC electrodes showing the best activities, $\Delta \mathrm{E}_{\mathrm{p}}<210$ $\mathrm{mV}$. The EIS spectra in Fig. 5 are made up of two distinct regions, a semicircle at high frequency whose radius depends on the charge transfer resistance $\left(\mathrm{R}_{\mathrm{CT}}\right)$ and a sloped line in the low frequency region associated with the Warburg impedance (W) corresponding to diffusion processes. The experimental data were fitted using the equivalent electrical circuit shown in Fig. 5. The equivalent circuit consists of an electrolyte resistance $\left(R_{E}\right)$, a charge transfer resistance $\left(\mathrm{R}_{\mathrm{CT}}\right)$, a Warburg impedance element $(\mathrm{W})$, and a constant phase element (CPE) denoted by ' $\mathrm{Q}$ '. A CPE was used to model the double layer capacitance $\left(\mathrm{C}_{\mathrm{DL}}\right)$ and account for the non-ideal behaviour of the capacitive elements due to surface inhomogeneity's including surface roughness and impurities $\left[32,33\right.$. Equation (2) gives the relationship between the CPE (Q) and the $\mathrm{C}_{\mathrm{DL}}$. Table 4 summarises the parameters determined from the model.

$C_{D L}=Q \cdot(\omega)^{a-1}$

Where ' $a$ ' is a dimensionless parameter $0<a<1$ and $a=1$ corresponds to an ideal capacitor, ' $Q$ ' is a constant with units $m F . s^{(a-1)}$, ' $\omega$ ' is the frequency $\left(s^{-1}\right)$ corresponding to the apex of the Nyquist diagram [33]. 


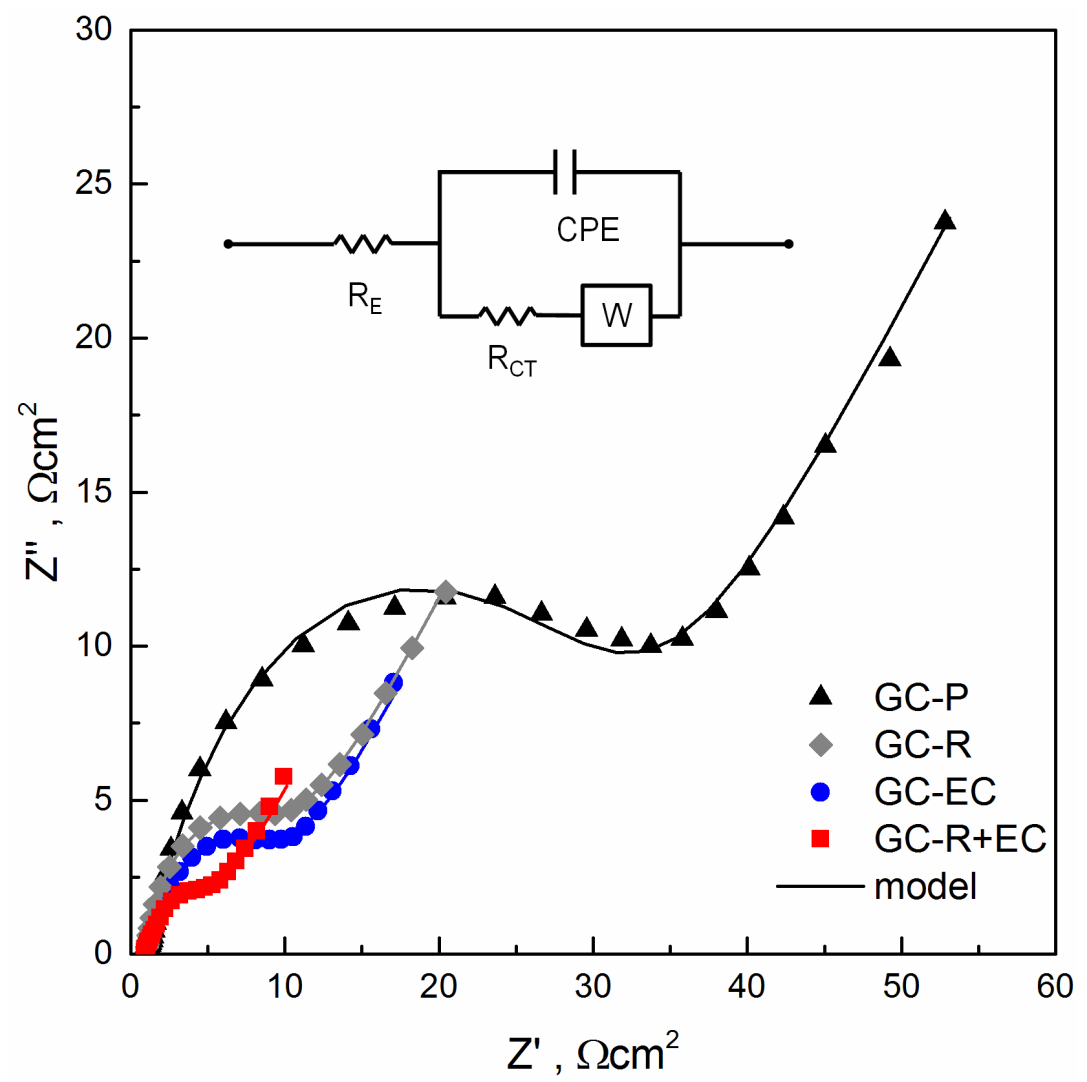

Fig. 5 - Nyquist impedance plots for GC-P, GC-EC, GC-R and GCR+EC electrodes recorded at $10 \mathrm{mV}$ overpotential. Experimental data are shown by markers and the model fit is shown by the solid lines. 
Table 4 - Equivalent electrical circuit parameters obtained from fitting experimental EIS data measured at $10 \mathrm{mV}$ overpotential in $0.9 \mathrm{M} \mathrm{V}(\mathrm{V}) / 2 \mathrm{M} \mathrm{H}_{2} \mathrm{SO}_{4}$ to the model circuit in Fig. 5.

\begin{tabular}{|c|c|c|c|c|c|c|}
\hline Electrode & $\begin{array}{l}\mathbf{R}_{\mathrm{E}}, \\
\Omega . \mathrm{cm}^{2}\end{array}$ & 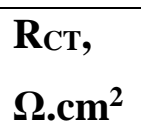 & $\begin{array}{l}\mathbf{W}, \\
\Omega \mathrm{s}^{-1 / 2}\end{array}$ & $\begin{array}{l}\mathbf{Q}, \\
\mathrm{mF} \cdot \mathbf{s}^{(\mathrm{a}-1)}\end{array}$ & $\mathbf{a}$ & $\chi^{2} 10^{-3 *}$ \\
\hline GC-P & 1.2 & 30.2 & 66.4 & 0.25 & 0.80 & 24.8 \\
\hline GC-EC & 0.9 & 9.2 & 33.0 & 0.94 & 0.76 & 3.0 \\
\hline GC-R & 1.0 & 8.7 & 46.6 & 0.57 & 0.90 & 3.0 \\
\hline $\mathrm{GC}-\mathrm{R}+\mathrm{EC}$ & 0.9 & 5.4 & 21.5 & 3.10 & 0.69 & 13.5 \\
\hline
\end{tabular}

$* \chi^{2}$ - fit accuracy

The $\mathrm{R}_{\mathrm{CT}}$ of the GC electrodes in Table 4 decreases in the order pristine GC-P > GC-EC > GC-R $>$ GC-R+EC indicating that the electron transfer rate has improved on these three modified GC electrodes. Moreover, this trend in the $\mathrm{R}_{\mathrm{CT}}$ is in line with the $\Delta \mathrm{E}_{\mathrm{p}}$ activity descriptor adopted in section 4.1 and validates the activity trends observed in terms of $\Delta \mathrm{E}_{\mathrm{p}}$. Looking at the low frequency region of the impedance spectra in Fig. 5, all GC electrodes show nearly ideal Warburg behavior with a phase angle close to $45^{\circ}$. High $\mathrm{W}$ values are characteristic of systems, which exhibit variations in ion diffusion path lengths, resulting in lower access of electrolyte ions to the active electrode surface [32]. The $\mathrm{W}$ values for the treated electrodes shown here decrease in the order GC-R> GC-EC > GC-R+EC. This behavior could be related to an increase in surface wettability when oxygen species are introduced onto the surface. As previously discussed, the GC-EC and GC-R+EC showed higher O/C ratios after treatment compared to the GC-R. The corresponding low $\mathrm{W}$ values for these two electrodes with high $\mathrm{O} / \mathrm{C}$ ratios suggest that the surface oxygen groups lead to better electrolyte accessibility to the electrode surface. Furthermore, The GC-R electrode shows a higher $\mathrm{W}$ value compared to the GC-EC and GC-R+EC. However, the charge transfer resistance $\left(\mathrm{R}_{\mathrm{CT}}\right)$ is similar on these three surfaces. This suggests that differences in $\mathrm{O} / \mathrm{C}$ ratios only contribute to the wetting properties of the surface (reflected by the $\mathrm{W}$ element) and do not play a catalytic role in the charge transfer process itself, this is in agreement with suggestions by previous authors [12, 34]. 


\subsection{Influence of surface $O / C$ ratio and carbon microstructure of $G C$ on $V(V)$ reduction activity}

It has been proposed by several authors that oxygen functional groups play a key role in facilitating the electron transfer process for $\mathrm{V}(\mathrm{V})$ reduction at carbon electrode surfaces $[8,18$, 35]. More recent studies have negated the catalytic role of oxygen groups towards $\mathrm{V}(\mathrm{V})$ reduction, and have suggested that other properties such as surface roughness and carbon microstructure play a role in improving electrode kinetics $[11,13,36]$. In order to gain further insight into the properties affecting activity from this study, activity trends with $\mathrm{O} / \mathrm{C}$ ratio and carbon structure were investigated. Plots of activity versus $\mathrm{O} / \mathrm{C}$ ratio and D-band peak width are shown in Fig. 6.
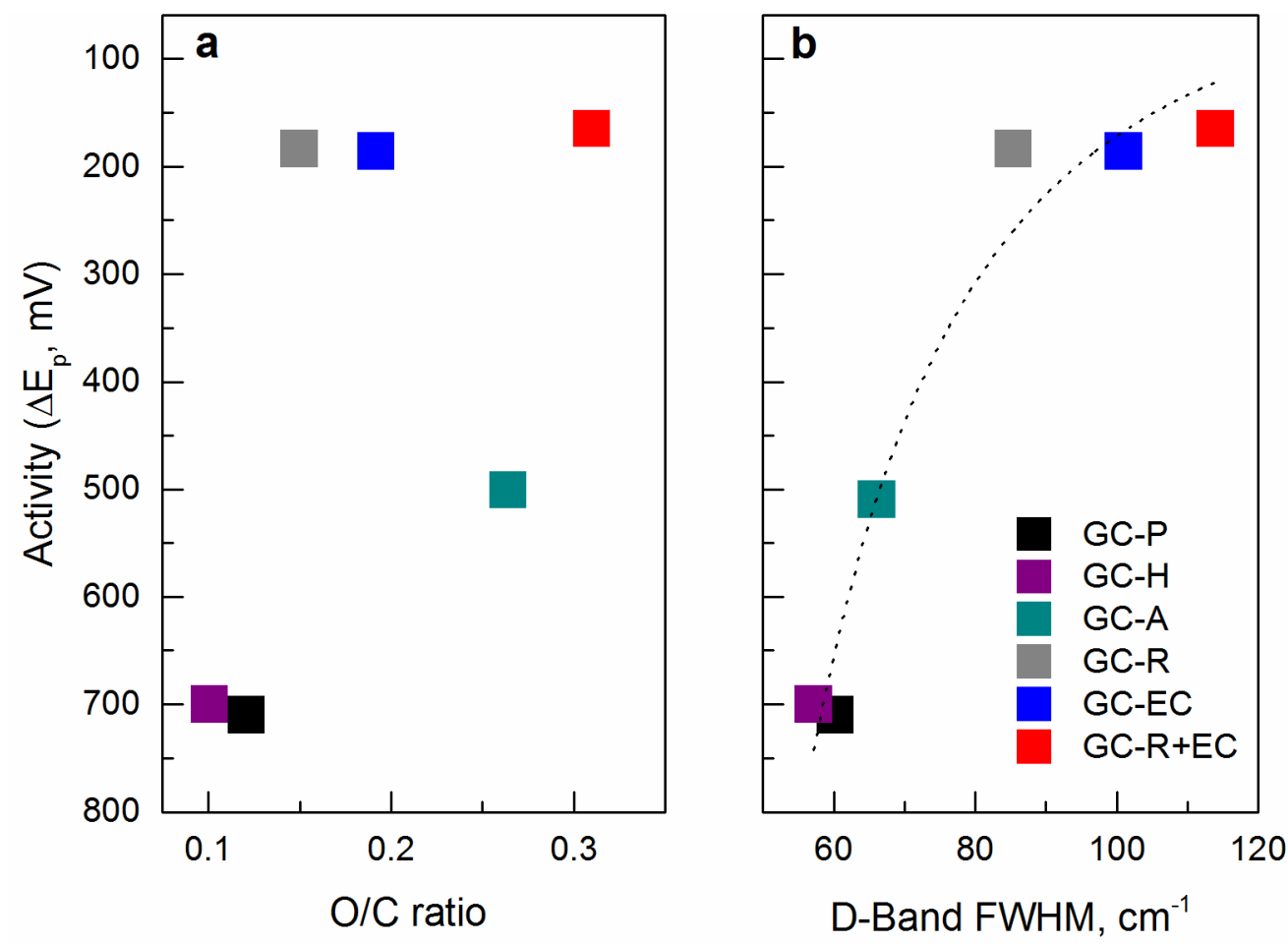

Fig. 6 - Activity $\left(\Delta E_{p}, m V\right)$ versus (a) surface oxygen to carbon ratio $(O / C)$ and (b) peak width of the D-Band from the Raman spectra measured as the FWHM $\left(\mathrm{cm}^{-1}\right)$ (the dotted line serves as a guide for the eye only).

It is clear from Fig. 6a that there is no direct correlation between $\mathrm{O} / \mathrm{C}$ ratio and activity. The GC$\mathrm{EC}, \mathrm{GC}-\mathrm{R}$ and the GC-R+EC surfaces show similar activities, however the $\mathrm{O} / \mathrm{C}$ ratios differ significantly on these three surfaces. Furthermore, XPS did not reveal any convincing trends 
relating activity with a specific oxygen functional group. An increase in both the carbonyl and carboxyl groups was observed for all treated electrode except the GC-R. However, GC-A and GC-H showed a much poorer activity compared to GC-EC and GC-R+EC despite an increase in the relative amounts of these two functional groups. This finding is in line with several recent studies which have suggested that oxygen groups may not play a key role in improving electrode kinetics for $\mathrm{V}(\mathrm{V})$ reduction and that other factors such as surface roughness, wettability and carbon microstructure could be more important $[11,13,36]$.

Fig. $6 \mathrm{~b}$ shows the correlation between the activity and the D-band peak width (FWHM). The peak width of the D-band was chosen as the parameter indicating a structural change, as it can be directly linked to the introduction of defects and disorder into the GC structure $[21,24,26]$. The D-band broadening itself appeared to be most prominent for the three most active surfaces in this study. Fig. $6 \mathrm{~b}$ confirms that higher activities were seen for GC samples which showed significant peak broadening of the D-band after treatment. In all three cases, the peak broadening was accompanied by a reduction in the D-band peak intensity, and a consequent lowering of the $\mathrm{I}_{\mathrm{D}} / \mathrm{I}_{\mathrm{G}}$ ratio. Thus a similar trend could be drawn for activity and $I_{D} / I_{G}$, where low $I_{D} / I_{G}$ ratios correspond to high activities. However, this interpretation is less intuitive and low $\mathrm{I}_{\mathrm{D}} / \mathrm{I}_{\mathrm{G}}$ ratios could be misinterpreted as an increase in order or graphitisation, which is not the case for GC in this study. Carbon structure appears to be an important property playing a key role in improving the electrode kinetics of $\mathrm{GC}$ towards the $\mathrm{V}(\mathrm{V})$ reduction reaction. The rough $\mathrm{GC}$ surface exhibited Raman features similar to the GC-EC, and GC-R+EC with observable D-band peak broadening and a lowering of the $\mathrm{I}_{\mathrm{D}} / \mathrm{I}_{\mathrm{G}}$ ratio, again interpreted as defect introduction. The $\mathrm{O} / \mathrm{C}$ was slightly greater than that of the GC-P. Thus, the significant activity improvement observed for this surface, suggests that defect introduction alone can improve V(V) reduction activity, and oxygen functionalities may not play a catalytic role for this reaction. However, oxygen functionalities may play a role in improving the mass transport properties and wetting of the GC surface as was suggested by the impedance spectroscopy interpretation in section 4.2.

Finally further electrochemical oxidation of the rough GC surface (GC-R+EC), resulted in an increase in surface oxygen to carbon ratio and a further D-band broadening observed by Raman spectroscopy. It is interesting to note here that despite even further changes in structural disorder and an increased $\mathrm{O} / \mathrm{C}$ ratio on the GC surface, the peak separation is not drastically improved, 
similar observations were made in a study by Cao et al. [13]. However, a lower Warburg impedance value indicates an improvement in mass transport (See Table 4.). This again suggests a mass transport improvement perhaps due to the increased surface $\mathrm{O} / \mathrm{C}$ ratios. The results shown here suggest that there is a limit of surface roughness or structural disorder of GC beyond which the activity is not improved significantly.

\section{Conclusions}

In this study the effect of oxygen functional groups and carbon microstructural changes on $\mathrm{V}(\mathrm{V})$ reduction activity were studied on a glassy carbon model electrode surface. No direct correlation between $\mathrm{V}(\mathrm{V})$ reduction activity and surface oxygen to carbon ratio or any specific oxygen functional group was found for this system. Significant structural changes were revealed by Raman spectroscopy for electrodes subjected to electrochemical oxidation, abrasive polishing and a combination of the two treatments. All of these surfaces showed improved activities and reduced charge transfer resistances towards $\mathrm{V}(\mathrm{V})$ reduction. The structural changes were interpreted as a disruption of the GC structure by introduction of defects, confirmed by D-band broadening and lowering of the $\mathrm{I}_{\mathrm{D}} / \mathrm{I}_{\mathrm{G}}$ ratio. It appears that the heat and acid treatments were not aggressive enough to induce substantial structural changes observable by Raman spectroscopy. The activity improvement observed for the GC-R surface suggests that defect introduction and structural changes alone can improve $\mathrm{V}(\mathrm{V})$ reduction activity, and the oxygen functionalities are not crucial to improving the catalytic activity of GC. Additional electrochemical oxidation of the rough GC, did not result in substantial activity improvements, despite a further change in structure and increased $\mathrm{O} / \mathrm{C}$ ratio. A possible explanation for this is that there is a limit of roughness or defect exposure and disorder, beyond which the activity $\left(\Delta \mathrm{E}_{\mathrm{p}}\right)$ cannot be further improved. Findings from this study complement a recent study by Cao et al. where surface roughness and defects were thought to play a role in activity for $\mathrm{V}(\mathrm{V})$ reduction [13]. The combination of electrochemical characterisation and Raman peak width analysis in this study has revealed valuable activity trends, which have not been seen previously by the commonly applied $\mathrm{I}_{\mathrm{D}} / \mathrm{I}_{\mathrm{G}}$ analysis. 


\section{Acknowledgements}

The authors thank The Swiss National Science Foundation for their financial support within the REPCOOL project (Grant No. 147 661).

\section{References}

[1] P. Leung, X. Li, C. Ponce de León, L. Berlouis, C. T. J. Low, and F. C. Walsh, "Progress in redox flow batteries, remaining challenges and their applications in energy storage," RSC Adv., vol. 2, no. 27, pp. 10125-1056, 2012.

[2] Y. A. Gandomi, D. S. Aaron, T. A. Zawodzinski, and M. M. Mench, "In Situ Potential Distribution Measurement and Validated Model for All-Vanadium Redox Flow Battery," J. Electrochem. Soc., vol. 163, no. 1, pp. A5188-A5201, 2016.

[3] K. J. Kim, M.-S. Park, Y.-J. Kim, J. H. Kim, S. X. Dou, and M. Skyllas-Kazacos, “A technology review of electrodes and reaction mechanisms in vanadium redox flow batteries," J. Mater. Chem. A, vol. 3, no. 33, pp. 16913-16933, 2015.

[4] J. Marschewski, S. Jung, P. Ruch, N. Prasad, S. Mazzotti, B. Michel, and D. Poulikakos, "Lab on a Chip overcoming the diffusion limit in co-laminar," Lab Chip, vol. 15, pp. 1923-1933, 2015.

[5] M. Skyllas-Kazacos, M. H. Chakrabarti, S. a. Hajimolana, F. S. Mjalli, and M. Saleem, "Progress in Flow Battery Research and Development," J. Electrochem. Soc., vol. 158, no. 8, pp. R55-R79, 2011.

[6] K. J. Kim, S.-W. Lee, T. Yim, J.-G. Kim, J. W. Choi, J. H. Kim, M.-S. Park, and Y.-J. Kim, "A new strategy for integrating abundant oxygen functional groups into carbon felt electrode for vanadium redox flow batteries.," Sci. Rep., vol. 4, p. 6906, 2014.

[7] B. Sun and M. Skyllas-Kazacos, "Modification of graphite electrode materials for vanadium redox flow battery application-I. Thermal treatment," Electrochim. Acta, vol. 37, no. 7, pp. 1253-1260, 1992.

[8] M. Gattrell, J. Park, B. MacDougall, J. Apte, S. McCarthy, and C. W. Wu, "Study of the Mechanism of the Vanadium 4+/5+ Redox Reaction in Acidic Solutions," J. Electrochem. Soc., vol. 151, no. 1, pp. A123-A130, 2004. 
[9] M. Ulaganathan, V. Aravindan, Q. Yan, S. Madhavi, M. Skyllas-Kazacos, and T. M. Lim, "Recent Advancements in All-Vanadium Redox Flow Batteries," Adv. Mater. Interfaces, vol. 3, p. 1500309, 2016.

[10] N. Pour, D. G. Kwabi, T. Carney, R. M. Darling, M. L. Perry, and Y. Shao-Horn, "Influence of Edge- and Basal-Plane Sites on the Vanadium Redox Kinetics for Flow Batteries," J. Phys. Chem. C, vol. 119, no. 10, pp. 5311-5318, 2015.

[11] J. Melke, P. Jakes, J. Langner, L. Riekehr, U. Kunz, Z. Zhao-Karger, A. Nefedov, H. Sezen, C. Wöll, H. Ehrenberg, and C. Roth, "Carbon materials for the positive electrode in all-vanadium redox flow batteries," Carbon N. Y., vol. 78, pp. 220-230, 2014.

[12] A. M. Pezeshki, J. T. Clement, G. M. Veith, T. A. Zawodzinski, and M. M. Mench, "High performance electrodes in vanadium redox flow batteries through oxygen-enriched thermal activation,” J. Power Sources, vol. 294, pp. 333-338, 2015.

[13] L. Cao, M. Skyllas-Kazacos, and D.-W. Wang, "Effects of Surface Pretreatment of Glassy Carbon on the Electrochemical Behavior of V(IV)/V(V) Redox Reaction," $J$.

Electrochem. Soc., vol. 163, no. 7, pp. A1164-A1174, 2016.

[14] J. Langner, M. Bruns, D. Dixon, A. Nefedov, C. Wöll, F. Scheiba, H. Ehrenberg, C. Roth, and J. Melke, "Surface properties and graphitization of polyacrylonitrile based fiber electrodes affecting the negative half-cell reaction in vanadium redox flow batteries," $J$. Power Sources, vol. 321, pp. 210-218, 2016.

[15] M. Park, I.-Y. Jeon, J. Ryu, J.-B. Baek, and J. Cho, "Exploration of the Effective Location of Surface Oxygen Defects in Graphene-Based Electrocatalysts for All-Vanadium RedoxFlow Batteries," Adv. Energy Mater., vol. 5, p. 1401550, 2015.

[16] A. Bourke, M. A. Miller, R. P. Lynch, X. Gao, J. Landon, J. S. Wainright, R. F. Savinell, and D. N. Buckley, "Electrode Kinetics of Vanadium Flow Batteries: Contrasting Responses of V II $-\mathrm{V}^{\mathrm{III}}$ and V IV $-\mathrm{V}^{\mathrm{V}}$ to Electrochemical Pretreatment of Carbon," $J$. Electrochem. Soc., vol. 163, no. 1, pp. A5097-A5105, 2016.

[17] M. G. Sullivan, B. Schnyder, M. Bärtsch, D. Alliata, C. Barbero, R. Imhof, and R. Kötz, "Electrochemically Modified Glassy Carbon for Capacitor Electrodes Characterization of 
Thick Anodic Layers by Cyclic Voltammetry, Differential,” J. Electrochem. Soc., vol. 147, no. 7, pp. 2636-2643, 2000.

[18] J. Friedl, C. M. Bauer, A. Rinaldi, and U. Stimming, "Electron transfer kinetics of the Reaction on multi-walled carbon nanotubes," Carbon N. Y., vol. 63, pp. 228-239, 2013.

[19] D. Yang, A. Velamakanni, G. Bozoklu, S. Park, M. Stoller, R. D. Piner, S. Stankovich, I. Jung, D. A. Field, C. A. Ventrice, and R. S. Ruoff, "Chemical analysis of graphene oxide films after heat and chemical treatments by X-ray photoelectron and Micro-Raman spectroscopy," Carbon N. Y., vol. 47, no. 1, pp. 145-152, 2009.

[20] G. Ilangovan and K. C. Pillai, "Electrochemical and XPS characterization of glassy carbon electrode surface effects on the preparation of a monomeric molybdate ( VI ) -modified electrode," Langmuir, vol. 13, no. 32, pp. 566-575, 1997.

[21] M. I. Nathan, J. E. Smith, and K. N. Tu, "Raman spectra of glassy carbon," J. Appl. Phys., vol. 45, no. 5, p. 2370, 1974.

[22] A. C. Ferrari and J. Robertson, "Interpretation of Raman spectra of disordered and amorphous carbon," Phys. Rev. B, vol. 61, no. 20, pp. 14095-14107, 2000.

[23] S. Reich and C. Thomsen, "Raman spectroscopy of graphite Raman spectroscopy of graphite,” phil. Trans. R. Soc. Lond. A, vol. 362, pp. 2271-2288, 2004.

[24] D. G. McCulloch, S. Prawer, and A. Hoffman, "Structural investigation of xenon-ionbeam-irradiated glassy carbon," Phys. Rev. B, vol. 50, no. 9, pp. 5905-1917, 1994.

[25] N. Larouche and B. L. Stansfield, "Classifying nanostructured carbons using graphitic indices derived from Raman spectra," Carbon N. Y., vol. 48, no. 3, pp. 620-629, 2010.

[26] K. Nakamura, M. Fujitsuka, and M. Kitajima, "Disorder-induced line broadening in firstorder Raman scattering from graphite," Phys. Rev. B, vol. 41, no. 17, pp. 12260-12263, 1990.

[27] R. L. Mccreery, "Advanced Carbon Electrode Materials for Molecular Electrochemistry," Chem. Rev., vol. 108, no. 7, pp. 2646-2687, 2008.

[28] K. Ray and R. L. McCreery, "Spatially resolved Raman spectroscopy of carbon electrode 
surfaces: Observations of structural and chemical heterogeneity," Anal. Chem., vol. 69, no. 22, pp. 4680-4687, 1997.

[29] A. Sadezky, H. Muckenhuber, H. Grothe, R. Niessner, and U. Poschl, "Raman microspectroscopy of soot and related carbonaceous materials: Spectral analysis and structural information," Carbon N. Y., vol. 43, no. 8, pp. 1731-1742, 2005.

[30] R. S. Nicholson, "Theory and Application of Cyclic Voltammetry f m Measurement of Electrode Reaction Kinetics,” Anal. Chem., vol. 37, no. 11, pp. 1351-1355, 1965.

[31] A. J. Bard and L. R. Faulkner, "Electrochemical Methods Fundamentals and Applications," Second. Hoboken NJ, John Wiley \& Sons, 2001.

[32] Ghodbane, O., Louro, M., Coustan, L., Patru, a. \& Favier, F. "Microstructural and Morphological Effects on Charge Storage Properties in MnO2-Carbon Nanofibers Based Supercapacitors". J. Electrochem. Soc. 160, A2315-A2321, 2013.

[33] G. J. Brug, a. L. G. van den Eeden, M. Sluyters-Rehbach, and J. H. Sluyters, "The analysis of electrode impedances complicated by the presence of a constant phase element," J. Electroanal. Chem. Interfacial Electrochem., vol. 176, no. 1-2, pp. 275-295, 1984.

[34] M.-A. Goulet, M. Skyllas-Kazacos, and E. Kjeang, "The importance of wetting in carbon paper electrodes for vanadium redox reactions," Carbon N. Y., vol. 101, pp. 390-398, 2016.

[35] J. Maruyama, T. Hasegawa, S. Iwasaki, T. Fukuhara, and M. Nogami, "Mechanism of Dioxovanadium Ion Reduction on Oxygen-Enriched Carbon Surface," J. Electrochem. Soc., vol. 160, no. 8, pp. A1293-A1298, 2013.

[36] H. Fink, J. Friedl, and U. Stimming, "The faster half-cell in a Vanadium Redox Flow Battery is determined by the electrode composition," J. Phys. Chem. C, ASAP, 2016. 